\title{
НОВЫЕ МЕТОДЫ ВЫЯВЛЕНИЯ АГГРАВАЦИИ И СИМУЛЯЦИИ У БОЛЬНЫХ С ОФТАЛЬМОПАТОЛОГИЕЙ ПРИ ПРОВЕДЕНИИ МЕДИКО-СОЦИАЛЬНОЙ ЭКСПЕРТИЗЫ
}

ROLE OF NEW METHODS FOR DETECTING MALINGERING AND SIMULATION PATIENTS WITH OPHTHALMOPATHOLOGY AIMED AT MEDICAL AND SOCIAL \section{EXPERTISE}

\section{T. Tlupova \\ D. Teuvazhukova \\ A. Teuvov \\ A. Baziev \\ Z. Lovpache}

Summary. The purpose of this workis to describenew methods for detecting aggravation and simulation in patients with ophthalmopathology during medical and social examination. For the study, a special device was developed (RF Patent No. 2269921), which makes it possible to determine visual acuity under various lighting conditions. 6 groups were formed: A (control group), with the results of which the indicators of groups A1 (patients with high myopia), A2 (with primary glaucoma), A3 (with partial optic nerve atrophy), A4 (with initial cataract), A5 (with a dry form of macular degeneration). The influence of light conditions on visual acuity was studied.

The research carried out makes it possible to predict the economic effect (savings of budgetary resources, recalculated for the year, about $5,000,000$ rubles). The results obtained confirm the important role of using the proposed method for determining the true values of visual acuity, in the early diagnosis of glaucoma, macular degeneration, optic nerve atrophy, in the conduct of medical and social expertise to determine aggravation and simulation.

Keywords: medical-social examination (ITU), ophthalmology, light exposure, glaucoma, macular degeneration, myopia.
Тлупова Тамара Гумаровна

Дочент, Кабардино-Балкарский государственный университет им. Х.М. Бербекова ttlupova@gmail.com

Теуважукова Диана Арсеновна Клинический ординатор, Северо-Осетинская Государственная Медицинская Академия

di.teu.00@mail.ru

Теувов Аслан Алексеевич

Дочент, Кабардино-Балкарский государственный университет им. Х.М. Бербекова

teuw@mail.ru

Базиев Артур Мухарбиевич

Дочент, Кабардино-Балкарский государственный университет им. Х. М. Бербекова

bazzaarth76@mail.ru

Ловпаче Зарема Нурийдиновна

Дочент, Кабардино-Балкарский государственный университет им. Х.М. Бербекова tanka70@yandex.ru

Аннотация. Цель работы - описать новые методы выявления аггравации и симуляции у больных с офтальмопатологией при проведении медико-социальной экспертизы. Для проведения исследования был разработан специальный прибор (Патент РФ № 2269921), позволяющий определять остроту зрения при различных условиях освещения. Сформировано 6 групп: A (контрольная группа), с результатами которой сравнивали показатели групп A1 (пациенты с миопией высокой степени), А2 (с первичной глаукомой), A3 (с частичной атрофией зрительного нерва), А4 (с начальной катарактой), А5 (с сухой формой макулодистрофии). Изучалось влияние световых условий на остроту зрения.

Проведенные исследования позволяют прогнозировать экономический эффект (экономию бюджетных ресурсов пересчете за год около 5000 000 руб.). Полученные результаты подтверждают важную роль использования предлагаемого нами метода для определения истинных значений остроты зрения, в ранней диагностике глаукомы, макулодистрофии, атрофия зрительного нерва, в проведении медико-социальной экспертизы для определения аггравации и симуляции.

Ключевые слова: медико-социальная экспертиза (МС)), офтальмология, освещенность, глаукома, макулярная дегенерация, миопия. 


\section{Ввемение}

И звестно, что уровень инвалидности увеличивается ежегодно в десятки раз и инвалидность стала одной из важнейших проблем современного общества. Если в 2000году на 10 тыс населения приходилось 16 инвалидов, то в 2010 году этот показатель увеличился до 173 [2]. Трудоспособность больных с заболеваниями органа зрения во многом зависит от состояния зрительных функций. Большое значение имеет точное определение степени нарушения функций у больного. Офтальмологические методы исследования являются, пожалуй, наиболее точными в медицине. Но определение истинной остроты зрения больного, будучи методом субъективным, нередко представляет собой значительные трудности. Последние усугубляются тем, что в практической деятельности окулист может столкнуться с фактами сознательного или бессознательного искажения истины, когда больной симулирует болезнь, которой на самом деле у него нет или же аггравирует, т.е. преувеличивает проявление имеющегося заболевания [1, 3].

Существуют так называемые контрольные методы для точного определения зрительных функций. Известен метод Жаваля: исследуемому показывают шрифт, перед которым перпендикулярно строчкам держат карандаш. Пациент свободно читает, если видит обоими глазами. При зрении одним глазом он должен поворачивать голову, так как карандаш заслоняет некоторые буквы. «Зеркальная проба» основана на том, что плоское зеркало дает мнимое изображение объекта на таком расстоянии позади зеркала, на котором объект расположен впереди зеркала, т.е. знаки видны на удвоенном расстоянии. Если исследуемый читал с 5м первую строку и продолжает ее читать в зеркале, то острота зрения равна 0,2, а не 0,1.

Симуляцию слепоты на один глаз можно обнаружить при исследовании прямой и содружественной реакции зрачков на свет (при полной слепоте на один глаз прямая реакция зрачка на свет отсутствует, содружественная - сохранена). Проба Снеллена с цветными стеклами основана на том, что красное стекло делает незаметными на светлом фоне знаки красного цвета, а на черном фоне - знаки зеленого цвета. Зеленое стекло, наоборот, делает неузнаваемыми на белом фоне знаки зеленого цвета, а на черном - красного.

Описанные методы в большинстве своем субъективны, требуют определенного напряжения, несколько устарели. Существующие в настоящее время современные уточняющие методы исследования, такие как флюоресцентная ангиография, ультразвуковые исследования кровотока в сосудах глаза, оптическая когерентная томография и электрофизиологические исследования, часто просто отсутствуют в поликлиниках и глазных стационарах, а возрастающая стоимость диагностического обследования, диктует необходимость разработки наиболее простых, доступных, быстрых методов оценки функционального состояния органа зрения.

\section{Шель работы}

Описать новые методы выявления аггравации и симуляции у больных с офтальмопатологией при проведении медико-социальной экспертизы (МСЭ).

\section{Материалы и метолы}

Мы сформировали 6 групп: А (контрольная группа), с результатами которой сравнивали показатели групп A1, A2, A3, A4, A5 с различными видами офтальмопатологии. Контрольная группа здоровых лиц состояла из водителей автотранспортного предприятия № 1 г. Нальчика. Так как требования к допуску управлением автомобиля в нашей стране одни из самых жестких в мире, для обследования здоровых лиц была выбрана именно эта категория работников.

Проведено обследование 100 здоровых водителей, все - мужчины в возрасте от 40 до 55 лет (средний возраст - 47,08) со стажем работы от 13 до 30 лет (средне 17,73). Главным условием для отбора было поставлено отсутствие у водителей ДТП за время его работы. Другое условие - чтобы это были соматически здоровые люди, не предъявляющие жалоб на общее состояние организма и на орган зрения, в частности. Острота зрения с коррекцией у всех отобранных была не ниже 1,0, показатели ВГД, поля зрения, цветоощущения соответствовали норме.

Группы A1, A2, A3, A4 и A5 (по 50 человек) формировались из пациентов глазного отделения Республиканской Клинической больницы. Группа А1 - пациенты с миопией высокой степени, А2 -с первичной глаукомой, АЗ - с частичной атрофией зрительного нерва, A4 - с начальной катарактой, A5 - с сухой формой макулодистрофии. Изучалось влияние световых условий на остроту зрения. Исследование зрительных функций включало исследование по общепринятым методикам (остроты зрения, рефракции и т.д.), и тонкие офтальмоэргономические тесты.

Для проведения эксперимента был разработан специальный прибор (Патент РФ № 2269921)[4]. Исследование остроты зрения проводилось в 2 этапа. Сначала определялась острота зрения при стандартном освещении, а затем проводилось исследование при изменении освещенности от минимальной 50Лк до максимальной 400Лк. Целью эксперимента является определение ве- 
Таблица 1. Влияние освещенности тестов на остроту зрения при офтальмопатологии

\begin{tabular}{|l|l|l|l|}
\multirow{2}{*}{ Офтальмопатология } & \multicolumn{2}{|l|}{ Освещенность (Лк) } & \multirow{2}{*}{$\delta$} \\
\cline { 2 - 4 } & $\mathbf{5 0}$ & $\mathbf{4 0 0}$ & $0,55 \pm 0,01$ \\
\hline Миопия & $1,05 \pm 0,24$ & $1,60 \pm 0,24$ & $0,12 \pm 0,04$ \\
\hline Глаукома & $0,9 \pm 0,20$ & $1,02 \pm 0,26$ & $0,20 \pm 0,02$ \\
\hline Атрофия зрительного нерва & $0,88 \pm 0,20$ & $1,08 \pm 0,27$ & $0,04 \pm 0,02$ \\
\hline Катаракта & $0,98 \pm 0,21$ & $0,94 \pm 0,26$ & $0,04 \pm 0,02$ \\
\hline Макулодистрофия & $0,76 \pm 0,20$ & $0,80 \pm 0,26$ & \\
\hline
\end{tabular}

Таблица 2. Распределение пациентов по нозологиям

\begin{tabular}{|l|l|l|}
\hline Нозология & Количество & $\%$ \\
\hline Катаракта & 41 & $29,5 \%$ \\
\hline Глаукома & 22 & $15,8 \%$ \\
\hline Макулодистрофия & 25 & $10,8 \%$ \\
\hline Ретинопатия & 16 & $12,9 \%$ \\
\hline Атрофия зрительного нерва & 17 & $5,2 \%$ \\
\hline Миопия & 36 & $25,8 \%$ \\
\hline Всего & 157 & $100 \%$ \\
\hline
\end{tabular}

Таблица 3. Динамика снижения диагностированной инвалидности за 2018-2000 годы

\begin{tabular}{|l|l|l|l|l|}
\hline № & Нозологии & $\mathbf{2 0 1 8}$ & 2019г & 2020г \\
\hline 1 & Глаукома & 60 & 52 & 43 \\
\hline 2 & Осложненная миопия & 44 & 31 & 19 \\
\hline 3 & Болезни хрусталика & 18 & 10 & 9 \\
\hline 4 & Дегенерация макулы & 24 & 19 & 13 \\
\hline 5 & Гиперметропия & 7 & 3 & 0 \\
\hline
\end{tabular}

личины приращения функции $\delta$, которая представляет собой разность этих значений, и сравнение ее с определенной нами нормой для каждого возраста и при офтальмопатологии.

\section{Результаты и обсужление}

Определена величина приращения функции $\delta$ в норме и при офтальмопатологии (табл. 1).

С помощью предлагаемого устройства для определения остроты зрения (Патент РФ № 2269921) проведено обследование 157 пациентам, направленным на медико-социальную экспертизу. Распределение пациентов по нозологиям представлено в таблице 2.

Использование предлагаемого нами устройства значительно ускорило и облегчило диагностику, помогло в обследовании и оказании своевременной медицинской помощи пациентам. 7 пациентов были направлены необоснованно на МСэ и не признаны инвалидами. Трем пациентам была определена истинная величина остроты зрения, и они переведены в другие категории нетрудоспособного населения (например, со 2 группы на 3). Благодаря использованию предлагаемого метода уменьшились показатели инвалидности (табл. 3).

Проведенные исследования позволяют прогнозировать определенный экономический эффект. По данным Пенсионного Фонда по КБР затраты государства на помощь одному инвалиду составляют в среднем 70000-80000 руб. в год. Нетрудно подсчитать, что только реабилитированные нами за один квартал 7 человек составят реальную экономию бюджетных ресурсов 500000-600000руб. А в пересчете за год — эта цифра будет приближаться к 5000000 руб. И это лишь по данным одной медико-социальной комиссии.

\section{Зак^ючение}

Таким образом, полученные нами результаты подтверждают важную роль использования предлагаемого нами метода при проведении медико-социальной экспертизы с целью определения аггравации и симуляции, для определения истинных значений остроты зрения, в ранней диагностике таких тяжелых заболеваний, как глаукома, макулодистрофия, атрофия зрительного нерва. 


\section{ЛИТЕРАТУРА}

1. Глазные болезни: Учебник / Под ред. В. Г. Капаевой. - М.: Медицина, 2002.560с.

2. Зелинская Д. И. Актуальные проблемы детской инвалидности // Детский доктор. 2000. № 1. С. 48-51.

3. Либман Е.С., Шахова Е. В. Слепота, слабовидение и инвалидность по зрению в Российской Федерации. Ликвидация устранимой слепоты. Всемирная инициатива В03 // Мат. Росс. межрегион. симпозиума. Уфа, 2003. С. 38-42.

4. Тлупова Т.Г., Чернышева С. Г., Розенблюм Ю. З. Устройство для определения остроты зрения. Патент РФ № 2269921 от 17.05.2004.

○ Тлупова Тамара Гумаровна ( ttlupova@gmail.com ), Теуважукова Диана Арсеновна ( di.teu.00@mail.ru ),

Теувов Аслан Алексеевич ( teuw@mail.ru ), Базиев Артур Мухарбиевич ( bazzaarth76@mail.ru ),

Ловпаче Зарема Нурийдиновна ( tanka70@yandex.ru ).

Журнал «Современная наука: актуальные проблемы теории и практики»

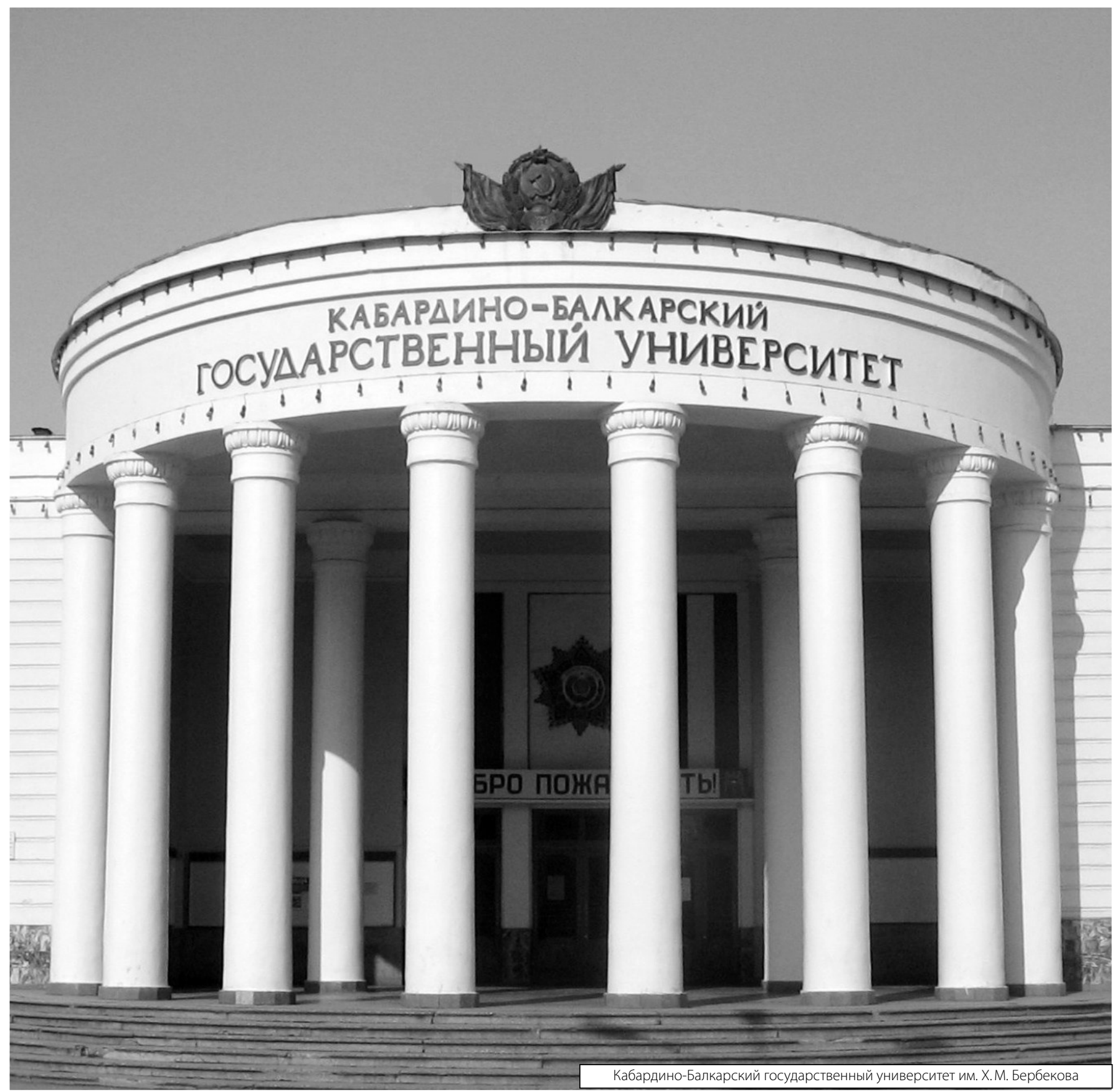

